\title{
Two-week Triple Therapy with either Standard or High-dose Esomeprazole for First-line H. pylori Eradication
}

\author{
Vincenzo De Francesco ${ }^{1}$, Lorenzo Ridola ${ }^{2}$, Cesare Hassan $^{3}$, Annamaria Bellesia $^{1}$, Domenico Alvaro ${ }^{2}$, Dino Vaira ${ }^{4}$, \\ Angelo Zullo ${ }^{3}$
}

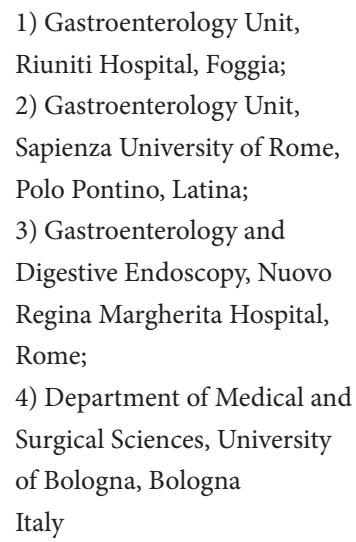

1) Gastroenterology Unit,

Riuniti Hospital, Foggia;

2) Gastroenterology Unit, Sapienza University of Rome, Polo Pontino, Latina;

3) Gastroenterology and Digestive Endoscopy, Nuovo Regina Margherita Hospital, Rome;

4) Department of Medical and Surgical Sciences, University of Bologna, Bologna Italy

\begin{abstract}
Background \& Aims: The updated Italian guidelines advise a standard 14-day triple therapy for first-line $H$. pylori eradication. This prospective study evaluated the cure rate following a 14-day triple therapy with either a standard or double-dose proton pump inhibitor (PPI).

Methods. A total of 145 consecutive patients with $H$. pylori infection were randomized to receive a 14-day, first-line triple therapy with clarithromycin $500 \mathrm{mg}$, amoxicillin $1 \mathrm{~g}$ and esomeprazole at either $20 \mathrm{mg}$ (standard therapy) or $40 \mathrm{mg}$ (double-dose therapy), each given twice daily.

Results. At intention-to-treat analysis, H. pylori infection was cured in 73.9\% (95\% CI: 63.9-84) and 81.9\% (95\% CI: 73-90.8) following standard and double-dose therapy, respectively, and in 78.2\% (95\% CI: 68.5-87.9) and $85.5 \%$ (95\% CI: 77.2-93.8) at per-protocol analysis. No statistically significant difference occurred. Overall, $16.4 \%$ and $19.4 \%$ patients in the standard and double-dose therapy regimen complained of side effects.

Conclusion. The success rate of both standard and double-dose 14-day triple therapies for first-line $H$. pylori treatment was unsatisfactory. A prolonged 14-day levofloxacin-based triple therapy for second-line $H$. $p y l o r i$ eradication seems to be promising.
\end{abstract}

Key words: Helicobacter pylori - triple therapy - levofloxacin - rescue therapy.

Abbrevations: ITT: Intention To Treat; NUD: non ulcer dyspepsia; PP: Per Protocol; PPI: proton pump inhibitors; PUD: peptic ulcer disease; UBT: urea breath test.

\section{INTRODUCTION}

In the last decade, the $H$. pylori eradication rate following standard 7-day triple therapies has fallen to unacceptably low cure rates worldwide [1]. This has been largely attributed to the increased prevalence of primary resistance towards clarithromycin and metronidazole, widely used for $H$. pylori treatment $[2,3]$. Therefore, current European guidelines suggest the use of a prolonged 10-14 days first-line triple therapy in those areas where primary clarithromycin resistance is $>15-20 \%$ [4]. In addition, the use of high-dose (twice daily) proton pump inhibitor (PPI) should be considered to further increase the efficacy of triple therapy [4]. The updated Italian guidelines advise a standard 14-day triple therapy for first-line $H$. pylori eradication [5]. However, following such a therapy, a cure rate less than the auspicated $90 \%$ was observed in some trials [6-8]. To our knowledge, no study has evaluated the efficacy of a 14-day triple therapy including double-dose PPI in Italy. We therefore designed a prospective study to evaluate the cure rate following a 14-day triple therapy with either standard or double-dose PPI in a central-southern Italian region with a high prevalence of clarithromycin resistance. As a secondary aim, the efficacy of a 14-day, levofloxacin-based triple therapy for second-line treatment in the eradication failure patients was tested.

\section{MATERIAL AND METHODS}

\section{Patients}

Consecutive patients complaining of dyspeptic symptoms referred for upper endoscopy in the participating three centres (Foggia, Rome, Latina) were considered for recruitment into the study. Exclusion criteria were: 1) age $<18$ years; 2) previous eradication therapy failures; 3 ) consumption of PPI and/or 
antibiotics in the previous two months; 4) previous gastric surgery; 5) liver cirrhosis or kidney failure, alcohol abuse, pregnancy, and known allergy to antibiotics. For all patients an informed consent was obtained.

\section{Endoscopy and $H$. pylori detection}

All patients underwent upper endoscopy, and five gastric biopsies were taken according to the updated Sydney System [9]. H. pylori infection was considered present when bacteria together with an active chronic gastritis were detected at histology, on Eosin \& Hematoxylin staining and modified Giemsa staining in doubtful cases, as performed in clinical practice. The presence of a peptic ulcer was defined as mucosal ulceration $>5 \mathrm{~mm}$ in diameter. For the purpose of the study, patients with duodenal or gastric ulcer were considered as having peptic ulcer disease (PUD), while those without macroscopic mucosal abnormalities were considered as nonulcer dyspeptic patients (NUD). Bacterial eradication was checked 6-8 weeks following therapy by using a standard ${ }^{13} \mathrm{C}$-urea breath test (UBT) with a cut-off value of $3.5 \%$, according to the manufacturer's recommendations. The UBT control was performed in laboratories not involved in the study.

\section{Therapy regimens}

This was a prospective, open-label, randomized study. Patients were randomized by a computer-generated list to receive a 14-day triple therapy with clarithromycin $500 \mathrm{mg}$, amoxicillin $1 \mathrm{~g}$ and esomeprazole at either $20 \mathrm{mg}$ or $40 \mathrm{mg}$ dose. All drugs were given twice daily, with PPI given half-hour before breakfast and dinner, and antibiotics following these meals. Patients were thoroughly instructed and motivated to the therapy. At the end of the treatment, both side effects and therapeutic compliance were assessed by personal interview. A pill intake $>90 \%$ was considered as good compliance. When first-line therapy failed, a second-line therapy regimen with esomeprazole $20 \mathrm{mg}$, amoxicillin $1 \mathrm{~g}$, and levofloxacin 250 mg, all twice daily, was administered for 14 days. The cost of therapies was calculated based on number of tablets required for the entire treatment by including only brand drugs.

\section{Statistical analysis}

Comparisons between patient groups were performed by using the T-test for unpaired data and the Chi-square test, as appropriate. The eradication rates with their 95\% confidence intervals (CIs) were calculated at both 'intention-to-treat' (ITT) and at 'per protocol' (PP) analyses. At ITT all the enrolled patients were included, whilst at PP only compliant patients who underwent UBT control were considered. Before pooling data, the observed eradication rates were compared to exclude a statistically significant difference among centres. Differences were considered significant at a 5\% probability level. SPSS was used for statistical analysis.

\section{RESULTS}

One-hundred and forty-five patients were enrolled from January to November 2015, including 73 and 72 patients in the standard and double-dose therapy regimen, all included at ITT analysis. A total of 7 patients were considered drop-outs due to either early therapy interruption for side-effects ( 3 cases) or because they had failed to attend the UBT control (4 cases). Therefore, there were 69 and 69 patients at PP analysis. No statistically significant differences were present between the two groups at entry, except of a higher prevalence of females in the standard regimen (Table I). Overall, 12 (16.4\%) and $14(19.4 \%)$ patients in the standard and double-dose therapy regimen complained of side-effects, including abdominal pain/ nausea (12), mild diarrhoea (11), metallic taste (3), itching (2), and urticaria (1). In 3 cases, the therapy was earlier stopped (at 3, 10 and 12 days).

Table I. Demographic and clinical characteristics of the enrolled patients.

\begin{tabular}{lccc}
\hline & $\begin{array}{c}\text { Standard-dose } \\
\text { PPI }\end{array}$ & $\begin{array}{c}\text { High-dose } \\
\text { PPI }\end{array}$ & P Value \\
\hline Number of patients & 73 & 72 & - \\
Age (mean \pm SD) years & $51.2 \pm 14.2$ & $47.9 \pm 15.8$ & 0.3 \\
Sex male/female & $21 / 52$ & $32 / 40$ & 0.0499 \\
Smoking habit (Yes/No) & $16 / 57$ & $25 / 47$ & 0.12 \\
Disease: NUD/PUD & $64 / 9$ & $68 / 4$ & 0.25 \\
\hline
\end{tabular}

PPI: proton pump inhibitor; NUD: non-ulcer dyspepsia; PUD: peptic ulcer disease.

As shown in Table II, the cure rate following the doubledose PPI regimen was higher than the standard-dose at both ITT $(+8 \%)$ and PP $(+7.3 \%)$, although the differences were not statistically significant. Moreover, only for the double-dose regimen the high 95\% CI limit was superior to 90\%, at both ITT and $\mathrm{PP}$ analysis. By considering all the 145 patients included in the PP analysis, the eradication rate tended to be lower in PUD than in NUD patients (69.2\% vs $83.2 \%)$, whilst similar cure rates occurred in males and females $(82.4 \%$ vs $81.4 \%)$, as well as in smokers and no smokers ( $81.3 \%$ vs $82.1 \%)$. In Italy, the cost of treatment was 44.82 and 54.71 Euros for standard and double-dose PPI regimen, respectively.

Table II. H. pylori eradication rates.

\begin{tabular}{lccc}
\hline Eradication rate & $\begin{array}{c}\text { Standard-dose } \\
\text { PPI }\end{array}$ & $\begin{array}{c}\text { Double-dose } \\
\text { PPI }\end{array}$ & P value \\
\hline $\begin{array}{l}\text { ITT analysis; N } \\
(\% ; 95 \% \mathrm{CI})\end{array}$ & $54 / 73$ & $59 / 72$ & 0.25 \\
PP analysis; N & $54.9 ; 63.9-84)$ & $(81.9 ; 73-90.8)$ & \\
$(\% ; 95 \% \mathrm{CI})$ & $(78.2 ; 8.5-87.9)$ & $(85.5 ; 7.2-93.8)$ & 0.27 \\
\hline
\end{tabular}

A total of 16 out of 25 eradication failure patients agreed to perform the second-line levofloxacin-based triple therapy. The infection was cured in 14 (87.5\%; 95\%CI 71.3-100). Compliance was good in all these patients, and side-effects occurred in $3(18.7 \%)$ cases, including mild diarrhoea (2 patients) and itching (1 patient).

\section{DISCUSSION}

Standard triple therapies remain the mostly used firstline treatment for $H$. pylori eradication in clinical practice. Unfortunately, the success rate following either 7-10 days triple 
therapies has declined to unacceptably low values in Italy [10], and several factors have been advocated as potential causes of therapy failure [11]. Therefore, the current European and Italian guidelines have suggested prolonging to 14 days the standard triple therapy duration in those areas with a high prevalence of primary clarithromycin resistance $[4,5]$. Indeed, it has been found that a longer triple therapy significantly increased the cure rate as compared to the 7-10 days regimen [12-16]. The use of increased PPI doses is another suggestion to improve the cure rate of triple therapies [4]. In Southern and Central Italy, where this study was performed, the prevalence rate of primary clarithromycin resistance has been found to be higher than $20 \%[17,18]$. Based on these observations, we peformed this study to test the efficacy of 14-day triple therapy with either standard or double PPI doses for first-line H. pylori eradication. Our data found that both these triple therapies achieved unsatisfactory eradication rates, with values $<80 \%$ at ITT analysis. In detail, the cure rate following the standard 14-day triple therapy regimen was consistent to $70-81.7 \%$ eradication rates achieved in other Italian studies [5-8], as well as to $74.8-82.2 \%$ observed in other countries, such as Germany, Korea, and Latin America [10, 19]. Following the 14-day triple therapy with double-dose PPI we observed a trend towards increased (7-8\%) eradication rates when compared to the standard regimen. However, even following this therapy the cure rate was $81.9-85.5 \%$. To our knowledge, the efficacy of this therapy regimen has been tested only in another study recently performed in Spain, where the eradication rates were 81.3-82.3\% [20]. Although modest, such a therapeutic gain in the presence of high clarithromycin resistance is probably clinically advantageous when considering that the cost of therapy, in Italy, is increased by only 10 Euros.

According to current guidelines $[4,5]$ we administered a levofloxacin-based triple regimen as a second-line therapy. Since we previously found that the cure rate following a standard 10-day regimen is decreasing, with an eradication rate ranging from to $55.6 \%$ to $72.6 \%$ [21-23], a 14-day therapy was chosen. Worth noting is that such a therapy achieved an encouragingly high (87.5\%) eradication rate. A similarly prolonged levofloxacin-based triple, with double-dose PPI, achieved 84.8-93.6\% success rates in Taiwan [24, 25]. However, when a regimen with increased doses was administered for only 8 days, the eradication rate was only $60-64 \%$ [26]. These observations suggest that the therapy duration of levofloxacinbased second-line therapy should be prolonged to 14 days rather than increasing the drugs dosage. Further studies are required to confirm these results. On the other hand, the threein-one pill, bismuth-based therapy could be useful as a rescue therapy, and its commercialization is awaited in our country.

\section{CONCLUSION}

The standard 14-day triple therapy seems to be unsuccessful for first-line H. pylori treatment in those areas with a high primary clarithromycin resistance, such as in Italy. Whether a double-dose PPI regimen is able to significantly increase the success rate needs to be proven in further studies. The efficacy of prolonged 14-day levofloxacin-based triple therapy for second-line H. pylori eradication seems to be promising.
Conflicts of interest: None to declare.

Authors' contribution: V.de F. and A.Z. designed the study, enrolled patients, and wrote the manuscript; C.H. analyzed the data; A.B. and L.R collected literature data; D.A. and D.V. performed internal critical revision. All authors approved the final version of the manuscript.

\section{REFERENCES}

1. Graham DY, Fischbach L. Helicobacter pylori treatment in the era of increasing antibiotic resistance. Gut 2010; 59: 1143-1153. doi: 10.1136/ gut.2009.192757

2. De Francesco V, Giorgio F, Hassan C, et al. Worldwide H. pylori antibiotic resistance: a systematic review. J Gastrointestin Liver Dis 2010; 19: 409-414.

3. Megraud F, Coenen S, Versporten A, et al. Helicobacter pylori resistance to antibiotics in Europe and its relationship to antibiotic consumption. Gut 2013; 62: 34-42. doi: 10.1136/gutjnl-2012-302254

4. Malfertheiner P, Megraud F, O'Morain CA, et al. Management of Helicobacter pylori infection - the Maastricht IV/Florence Consensus Report. Gut 2012; 61: 646-664. doi: 10.1136/gutjnl-2012-302084

5. Zagari RM, Romano M, Ojetti V, et al. Guidelines for the management of Helicobacter pylori infection in Italy. The III Working Group Consensus Report 2015. Dig Liver Dis 2015; 47: 903-912. doi: 10.1016/j. dld.2015.06.010

6. Zagari RM, Bianchi-Porro G, Fiocca R, Gasbarrini G, Roda E, Bazzoli F. Comparison of one and two weeks of omeprazole, amoxicillin and clarithromycin treatment for Helicobacter pylori eradication: the HYPER study. Gut 2007; 56: 475-479. doi: 10.1136/gut.2006.102269

7. Paoluzi P, Iacopini F, Crispino P, et al. 2-week triple therapy for Helicobacter pylori infection is better than 1-week in clinical practice: a large prospective single-center randomized study. Helicobacter 2006; 11: 562-568. doi: 10.1111/j.1523-5378.2006.00459.x

8. Zullo A, Severi C, Vannella L, Hassan C, Sbrozzi-Vanni A, Annibale B. Role of gastritis pattern on Helicobacter pylori eradication. Intern Emerg Med 2012; 7: 517-522. doi: 10.1007/s11739-011-0730-4

9. Dixon MF, Genta RM, Yardley JH, Correa P. Classification and grading of gastritis. The updated Sydney System. International Workshop on the Histopathology of Gastritis, Houston 1994. Am J Surg Pathol 1996; 20: 1161-1181.

10. Zullo A, Hassan C, Ridola L, De Francesco V, Vaira D. Standard triple and sequential therapies for Helicobacter pylori eradication: an update. Eur J Intern Med 2013; 24: 16-19. doi: 10.1016/j.ejim.2012.07.006

11. Zullo A, De Francesco V, Hassan C. Predicting Helicobacter pylori eradication: How to teach an old dog new tricks! J Clin Gastroenterol 2012; 46: 259-261. doi: 10.1097/MCG.0b013e318247177e

12. Fuccio L, Minardi ME, Zagari RM, Grilli D, Magrini N, Bazzoli F. Meta-analysis: duration of first-line proton-pump inhibitor-based triple therapy for Helicobacter pylori eradication. Ann Intern Med 2007; 147: 553-562. doi: 10.7326/0003-4819-147-8-200710160-00008

13. Gatta L, Vakil N, Leandro G, Di Mario F, Vaira D. Sequential therapy or triple therapy for Helicobacter pylori infection: systematic review and meta-analysis of randomized controlled trials in adults and children. Am J Gastroenterol 2009; 104: 3069-3079. doi: 10.1038/ajg.2009.555

14. Gatta L, Vakil N, Vaira D, Scarpignato C. Global eradication rates for Helicobacter pylori infection: systematic review and meta-analysis of sequential therapy. BMJ 2013; 347: f4587. doi: 10.1136/bmj.f4587 
15. Li BZ, Threapleton DE, Wang JY, et al. Comparative effectiveness and tolerance of treatments for Helicobacter pylori: systematic review and network meta-analysis. BMJ 2015; 351: h4052. doi: 10.1136/bmj.h4052

16. Liou JM, Chen CC, Chang CY, et al; Taiwan Gastrointestinal Disease and Helicobacter Consortium. Sequential therapy for 10 days versus triple therapy for 14 days in the eradication of Helicobacter pylori in the community and hospital populations: a randomised trial. Gut 2015 Sep 3. doi: 10.1136/gutjnl-2015-310142

17. De Francesco V, Margiotta M, Zullo A, et al. Primary clarithromycin resistance in Italy assessed on Helicobacter pylori DNA sequences by TaqMan real-time polymerase chain reaction. Aliment Pharmacol Ther 2006; 23: 429-435. doi: 10.1111/j.1365-2036.2006.02769.x

18. De Francesco V, Margiotta M, Zullo A, et al. Prevalence of primary clarithromycin resistance in Helicobacter pylori strains over a 15 year period in Italy. J Antimicrob Chemother 2007; 59: 783-785. doi: 10.1093/ $\mathrm{jac} / \mathrm{dkm} 005$

19. Dammann HG, Folsch UR, Hahn EG, et al. Eradication of H. pylori with pantoprazole, clarithromycin, and metronidazole in duodenal ulcer patients: a head-to-head comparison between two regimens of different duration. Helicobacter 2000; 5: 41-51. doi: 10.1046/j.15235378.2000.00006.x

20. Molina-Infante J, Lucendo AJ, Angueira T, et al. Optimised empiric triple and concomitant therapy for Helicobacter pylori eradication in clinical practice: the OPTRICON study. Aliment Pharmacol Ther 2015; 41: 581-589. doi: 10.1111/apt.13069

21. Zullo A, De Francesco V, Manes G, Scaccianoce G, Cristofari F, Hassan C. Second-line and rescue therapies for Helicobacter pylori eradication in clinical practice. J Gastrointestin Liver Dis 2010; 19: 131-134.

22. De Francesco V, Hassan C, Ridola L, Giorgio F, Ierardi E, Zullo A. Sequential, concomitant and hybrid first-line therapies for Helicobacter pylori eradication: a prospective randomized study. J Med Microbiol 2014; 63: 748-752. doi: 10.1099/jmm.0.072322-0

23. Zullo A, Scaccianoce G, De Francesco V, et al. Concomitant, sequential, and hybrid therapy for H. pylori. A pilot study. Clin Res Hepatol Gastroenterol 2013; 37: 647-650. doi: 10.1016/j.clinre.2013.04.003

24. Tai WC, Lee $\mathrm{CH}$, Chiou SS, et al. The clinical and bacteriological factors for optimal levofloxacin-containing triple therapy in secondline Helicobacter pylori eradication. PLoS ONE 2014; 9: e105822. doi: 10.1371/journal.pone.0105822

25. Chuah SK, Tai WC, Hsu PI, et al. The efficacy of second-line antiHelicobacter pylori therapy using an extended 14-days levofloxacin/ amoxicillin/proton pump inhibitors - a pilot study. Helicobacter 2012; 17: 374-381. doi: 10.1111/j.1523-5378.2012.00960.x

26. Zullo A, Ridola L, Efrati C, et al. First- and second-line Helicobacter pylori eradication with modified sequential therapy and modified levofloxacinamoxicillin-based triple therapy. Ann Gastroenterol 2014; 27: 357-361. 